\section{Case Reports in Neurology}

Case Rep Neurol 2021;13:200-204

DOI: $10.1159 / 000514244$

Published online: March 19, 2021

C) 2021 The Author(s)

Published by S. Karger AG, Basel

www.karger.com/crn

This article is licensed under the Creative Commons Attribution-NonCommercial 4.0 International License (CC BY-NC) (http://www.karger.com/Services/OpenAccessLicense) Usage and distribution for commercial purposes requires written permission.

\title{
Diabetic Cystopathy Occurs Independently from Other Atherosclerotic Risks
}

\author{
Osamu Takahashi ${ }^{a} \quad$ Ryuji Sakakibara $^{\mathrm{b}} \quad$ Ayami Shimizu $^{\mathrm{a}}$ Fuyuki Tateno $^{\mathrm{b}}$ \\ Yosuke Aibab \\ ${ }^{a}$ Clinical Physiology Unit, Sakura Medical Center, Toho University, Sakura, Japan; \\ ${ }^{b}$ Neurology, Internal Medicine, Sakura Medical Center, Toho University, Sakura, Japan
}

\section{Keywords}

Diabetes · Cystopathy · Atherosclerosis · Cardio-ankle vascular stiffness index · Carotid Doppler ultrasonography

\begin{abstract}
It has not yet been clarified whether atherosclerotic risks other than diabetes are related to bladder small fiber neuropathy (cystopathy) in type 2 diabetes. The aim of this study was to answer this question by urodynamics. This was a retrospective study. The subjects were 44 patients: 27 male, 17 female; mean age $67.0 \pm 12.7$ years; mean duration of diabetes $16.8 \pm$ 13.1 years; mean $\mathrm{HbA} 1 \mathrm{c} 7.8 \pm 1.2 \%$. We analyzed the relationship between diabetic cystopathy (at least one of the following abnormalities in urodynamics: decreased bladder sensation, postvoid residual, detrusor overactivity, low-compliance detrusor) and clinical items, i.e., severity and duration of diabetes, nerve conduction, body mass index, blood pressure, cardio-ankle vascular stiffness index, and ultrasound Doppler echography (plaque score, intima-media thickness) in these patients. As a result, urodynamic diabetic cystopathy was not correlated with any of the above systemic items. In conclusion, the above findings suggest that bladder small fiber neuropathy can occur independently from systemic atherosclerotic risks.
\end{abstract}

\begin{tabular}{ll}
\hline & Ryuji Sakakibara \\
Neurology, Internal Medicine \\
Sakura Medical Center, Toho University \\
$564-1$ Shimoshizu, Sakura, 285-8741 (Japan) \\
sakakibara@sakura.med.toho-u.ac.jp
\end{tabular}




\section{Case Reports in Neurology}

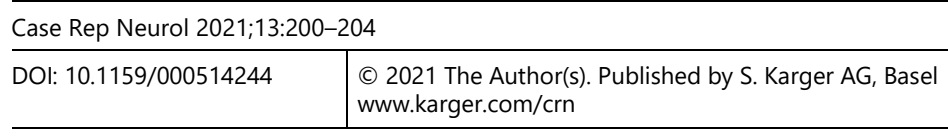

Takahashi et al.: Diabetic Cystopathy and Atherosclerosis

\section{Introduction}

Type 2 diabetes is known to cause bladder small fiber neuropathy (also called cystopathy) [1], with symptoms ranging from loss of bladder sensation to post-void residual [2, 3]. In contrast, it has not been clarified whether systemic atherosclerotic risks other than diabetes are related to diabetic cystopathy. The goal of this study was to address this question by urodynamics as the objective bladder measure.

\section{Subjects and Methods}

This was a retrospective study. Subjects were 44 type 2 diabetes [4] patients referred to our institution because of their lower urinary tract symptoms. All subjects were evaluated in our outpatient clinic: 27 male, 17 female; mean age $67.0 \pm 12.7$ years; mean duration of diabetes $16.8 \pm 13.1$ years; mean HbA1c $7.8 \pm 1.2 \%$. Most were receiving treatment, such as oral sulfonylurea, thiazolidine derivatives, dipeptidyl peptidase- 4 inhibitors, or insulin. All patients were able to walk independently.

In these patients we analyzed the relationship between diabetic cystopathy (at least one of the following objective abnormalities in urodynamics: decreased bladder sensation [first sensation $>300 \mathrm{~mL}$ or bladder capacity $>600 \mathrm{~mL}]$, detrusor overactivity, low-compliance detrusor [storage phase items], detrusor underactivity, and post-void residual [ $>50 \mathrm{~mL}$, voiding phase item]) with systemic factors, such as severity and duration of diabetes, nerve conduction abnormality (defined as Dyck's criteria $\geq 7$, i.e., a total of five nerve conduction abnormalities [5]), body mass index, blood pressure, cardio-ankle vascular stiffness index, and Doppler echography (plaque score, intima-media thickness). Patients with comorbid diseases/conditions such as prostatic hyperplasia (ultrasound-measured volume $>30 \mathrm{~mL}$ ), urological/psychiatric drugs, alcoholism, uremia, or amyloidosis that might cause limb neuropathy/lower urinary tract dysfunction (LUTD) were excluded.

The test methods for determining LUTD (using equipment from Urovision and Life-Tech Inc., Houston, TX, USA) were according to the International Continence Society standards. They included ultrasound echography of the prostate gland in all men (men with a prostate volume $>20$ mL were excluded), a nerve conduction study (Neuropack M2; Nihon Kohden Inc., Tokyo, Japan), a cardio-ankle vascular stiffness index test [6] (pulse wave velocity-derived parameter) using a VaSera instrument (Fukuda Denshi Inc., Tokyo, Japan), and an ultrasound Doppler echography (SSA-260A; Toshiba, Inc, Tokyo, Japan). Data were analyzed by Student's $t$ test and Mann-Whitney $\mathrm{U}$ test.

\section{Results}

Our results indicated that there were no significant correlations between objective urodynamic diabetic cystopathy and any of the above systemic factors (Table 1). We also performed two validated questionnaires - the overactive bladder symptom score (storage 


\section{Case Reports in Neurology}

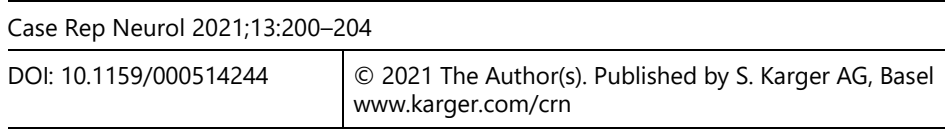

Takahashi et al.: Diabetic Cystopathy and Atherosclerosis

symptoms) and the international prostate symptom score (mainly voiding symptoms) - and there was no relationship between atherosclerotic factors either (data not shown).

\section{Discussion}

It is possible that a close relationship between LUTD and a systemic condition might contribute to the pathogenesis, prognosis, and management of diabetic cystopathy. To our knowledge, no study has assessed whether urodynamic diabetic cystopathy is correlated with atherosclerotic risks other than diabetes itself. Previous studies have suggested a relationship between diabetic cystopathy and the severity [7] and time course [3] of type 2 diabetes. Diabetic cystopathy in type 2 diabetes, which is mainly autonomic small-diameter myelinated/ unmyelinated fiber neuropathy, has been said to occur together with large-diameter myelinated fiber limb neuropathy [8]. On the other hand, it has also been suggested that diabetic cystopathy occurs independently from limb neuropathy [9]. The exact reason for this discrepancy is unknown. However, Dyck et al. [10] reported that diabetic limb polyneuropathy most commonly represents metabolic derangements that are secondary to chronic hyperglycemia such as polyol shunting, accumulation of advanced glycation end products, oxidative stress, and lipid abnormalities. Microvascular alterations with mild mechanical trauma, inflammation, microvasculitis, and ischemia are also causative factors [10]. In contrast, molecular changes in autonomic small-diameter myelinated/unmyelinated fiber in type 2 diabetes remain to be clarified $[11,12]$ and may have different pathophysiology from limb neuropathy.

The limitations of this study include the relatively small number of patients and the fact that it was a retrospective study following a single cohort. Nevertheless, our results contribute to the information regarding the care of patients with diabetic cystopathy, which affects quality of life in patients. Future prospective studies of a large cohort to further observe the relationship are warranted.

In conclusion, the present study results show that urodynamic diabetic cystopathy is not significantly correlated with atherosclerotic risks, suggesting that diabetic cystopathy can occur independently from systemic atherosclerotic risks.

\section{Statement of Ethics}

The present research complied with the guidelines for human studies, and the research was conducted ethically in accordance with the World Medical Association Declaration of Helsinki. All the patients gave their written informed consent. The present research was approved by the Ethics Committee of Sakura Medical Center, Toho University (2011-059).

\section{Conflict of Interest Statement}

The authors have no conflicts of interest to declare.

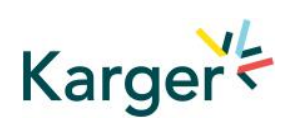




\section{Case Reports in Neurology}

Case Rep Neurol 2021;13:200-204

DOI: $10.1159 / 000514244$

(C) 2021 The Author(s). Published by S. Karger AG, Basel www.karger.com/crn

Takahashi et al.: Diabetic Cystopathy and Atherosclerosis

\section{Funding Sources}

The authors have no funding sources to declare.

\section{Author Contributions}

A. Shimizu: acquisition, analysis, and interpretation of data. R. Sakakibara: study concept and design, acquisition of subjects and/or data, analysis and interpretation of data, and manuscript preparation. O. Takahashi: acquisition, analysis, and interpretation of data. F. Tateno and Y. Aiba: acquisition of subjects and/or data.

\section{References}

1 Wittig L, Carlson KV, Andrews JM, Crump RT, Baverstock RJ. Diabetic bladder dysfunction: a review. Urology. 2019 Jan;123:1-6.

2 Sakakibara R, Tateno F, Sugiyama M, Takahashi O, Nishimura H, Kishi M, et al. How to measure bladder sensation in peripheral nerve diseases? Curr Bladder Dysfunct Rep. 2017;12(4):241-5.

3 Yamaguchi C, Sakakibara R, Uchiyama T, Yamamoto T, Ito T, Liu Z, et al. Overactive bladder in diabetes: a peripheral or central mechanism? Neurourol Urodyn. 2007;26(6):807-13.

4 Seino Y, Nanjo K, Tajima N, Kadowaki T, Kashiwagi A, Araki E, et al.; Committee of the Japan Diabetes Society on the Diagnostic Criteria of Diabetes Mellitus. Report of the committee on the classification and diagnostic criteria of diabetes mellitus. J Diabetes Investig. 2010 Oct;1(5):212-28.

5 Dyck PJ, Albers JW, Andersen H, Arezzo JC, Biessels GJ, Bril V, et al.; Toronto Expert Panel on Diabetic Neuropathy. Diabetic polyneuropathies: update on research definition, diagnostic criteria and estimation of severity. Diabetes Metab Res Rev. 2011 Oct;27(7):620-8.

6 Shimizu A, Sakakibara R, Takahashi O, Tateno F, Aiba Y. Bladder overactivity and post-void residual: which relates more to systemic atherosclerotic markers? Auton Neurosci. 2020 Jan;223:102600.

7 Wang R, Lefevre R, Hacker MR, Golen TH. Diabetes, glycemic control, and urinary incontinence in women. Female Pelvic Med Reconstr Surg. 2015 Sep-Oct;21(5):293-7.

8 Mitsui T, Kakizaki H, Kobayashi S, Morita H, Matsumura K, Koyanagi T. Vesicourethral function in diabetic patients: association of abnormal nerve conduction velocity with vesicourethral dysfunction. Neurourol Urodyn. 1999;18(6):639-45.

9 Sakakibara R, Takahashi O, Nishimura H, Tateno F, Kishi M, Tsuyusaki Y, et al. The relationship between bladder, periarterial and somatic neuropathy in diabetes. Intern Med. 2018 Aug;57(15):2165-8.

10 Dyck PJ, Clark VM, Overland CJ, Davies JL, Pach JM, Dyck PJ, et al. Impaired glycemia and diabetic polyneuropathy: the OC IG Survey. Diabetes Care. 2012 Mar;35(3):584-91.

11 Cao N, Gu B, Gotoh D, Yoshimura N. Time-dependent changes of urethral function in diabetes mellitus: a review. Int Neurourol J. 2019 Jun;23(2):91-9.

12 Masuda K, Aizawa N, Watanabe D, Okegawa T, Kume H, Igawa Y, et al. Pathophysiological changes of the lower urinary tract behind voiding dysfunction in streptozotocin-induced long-term diabetic rats. Sci Rep. 2020 Mar;10(1):4182. 
Case Reports in

Neurology
Case Rep Neurol 2021;13:200-204 \begin{tabular}{l|l}
\hline DOI: $10.1159 / 000514244$ & $\begin{array}{l}\text { (c) } 2021 \text { The Author(s). Published by S. Karger AG, Basel } \\
\text { www.karger.com/crn }\end{array}$
\end{tabular}

Takahashi et al.: Diabetic Cystopathy and Atherosclerosis

Table 1. Relationship between urodynamic LUTD and clinical risk factors in diabetes

\begin{tabular}{|c|c|c|c|}
\hline & $\begin{array}{l}\text { Urodynamic } \\
\text { LUTD - }\end{array}$ & $\begin{array}{l}\text { Urodynamic } \\
\text { LUTD + }\end{array}$ & $p$ value \\
\hline Age, years & $67.9 \pm 10.7$ & $66.4 \pm 13.6$ & ns \\
\hline Duration of diabetes, years & $17.9 \pm 15.3$ & $16.3 \pm 11.9$ & ns \\
\hline $\mathrm{HbA1c}, \%$ & $7.7 \pm 0.9$ & $8 \pm 1.5$ & ns \\
\hline Blood glucose, mg/dL & $201.3 \pm 91.2$ & $192.6 \pm 93$ & ns \\
\hline Large fiber neuropathy (by nerve conduction study of the extremities), \% & 71.4 & 86.7 & ns \\
\hline Obesity (body mass index), $\% 1$ & $23.4 \pm 4.1$ & $22.7 \pm 4.5$ & ns \\
\hline Systolic blood pressure, mm Hg${ }^{1}$ & $141.6 \pm 24.2$ & $148.4 \pm 29.3$ & ns \\
\hline Diastolic blood pressure, mm $\mathrm{Hg}^{1}$ & $77.2 \pm 11.6$ & $90 \pm 19.7$ & ns \\
\hline Cardio-ankle vascular stiffness index ${ }^{1}$ & $9.6 \pm 1.0$ & $9.8 \pm 1.2$ & ns \\
\hline Carotid Doppler echography (plaque score) $^{1}$ & $7.9 \pm 5.7$ & $9 \pm 5.4$ & ns \\
\hline Carotid Doppler echography (intima-media thickness), mm & $0.9 \pm 0.24$ & $0.8 \pm 0.2$ & ns \\
\hline
\end{tabular}

LUTD, lower urinary tract dysfunction. ${ }^{1}$ Atherosclerotic risks other than diabetes. 